\title{
Widely Acclaimed but Lowly Utilized: Congruencing ODL Utilization with its Wide Acclaim
}

\author{
Paul Birevu Muyinda ${ }^{1, *}$, Godfrey Mayende $^{1}$, Gilbert Maiga $^{2}$, Benedict Oyo $^{3}$ \\ ${ }^{1}$ College of Education and External Studies, Makerere University, Uganda \\ ${ }^{2}$ College of Computing and Information Sciences, Makerere University, Uganda \\ ${ }^{3}$ Department of Computer Science, Gulu University, Uganda
}

Copyright $\bigcirc 2019$ by authors, all rights reserved. Authors agree that this article remains permanently open access under the terms of the Creative Commons Attribution License 4.0 International License

\begin{abstract}
World over, open distance learning (ODL) is widely articulated and vouchered as a panacea pedagogy for increased access and flexibility to higher education. In reality, however, the actual use of ODL approaches in higher institutions of learning in developing regions is unexpectedly low and not in tandem with its wide favorable regional and international vouchering. This paper has the goal to suggest a framework for congruencing the low utilization levels of ODL approaches with their wide acclaim. Using a cross sectional survey, an inquiry was conducted among faculty across institutions of higher learning in Uganda to establish i) the factors explaining the wide acclaim for ODL; ii) the utilization level of ODL; iii) the factors that explain the present utilization levels of ODL; and iv) a framework for congruencing low ODL utilization with the hype surrounding it. The study revealed that being an ICT-driven pedagogy, ODL has the potential to transform higher education since ICTs are transforming other sectors. Further, the majority of institutions have put in place policies to spur ODL, but even then, ODL utilization has largely remained voluntary, implying lack of policy enforcement. This has left about $50 \%$ of the faculty with no presence whatsoever on their universities' LMSs. Low utilization was explained by factors personal or institutional in nature. Personal factors related to lack of will by faculty to get out of their perceived comfort zones and limited ODL pedagogy capacity. Institutional factors related to limited connectivity and access to ICT systems. Others were defective LMSs and lack of ODL pedagogy support. Institutions wishing to spur ODL utilization must first address people issues (soft dimensions) as they address the technological issues (hard dimensions). This way the hype will match the reality.
\end{abstract}

Keywords Blended Learning, Distance Learning, eLearning, ODeL, ODL, Open Learning, Online Learning

\section{Introduction}

\subsection{Overview}

Open Distance Learning is a pedagogy in which the learner and teacher are separated by time and space from their alma- mata. Learner and teacher interaction in ODL is abetted by ICTs and/ or specially designed study materials. ODL approaches may take the form of online learning, distance education, electronic learning (e-Learning), mobile learning (m-Learning) or blended learning (b-Learning).

ODL is widely acclaimed in international, regional, national and institutional spheres as a pedagogy with the affordance of accessibility, flexibility and affordability. This high acclaim has however remained as hype because on the ground, use of ODL approaches remains decimally low especially in the developing region of Africa.

Numerous studies have been undertaken to study uptake of ODL approaches in institutions of higher learning but studies to congruence utilization of these approaches with the hype accorded to them are still in their infancy. This paper uses a mixed research approach to study ODL use in public universities in Uganda from which a framework to congruence utilization of ODL approaches with their hype is developed. The paper is organized in five (5) sections. In Section 1, the introductory section, the paper provides a) an overview of the research, b) the place of ODL in international, regional, national and institutional development agendas, frameworks and policies; c) some ODL projects and conferences; c) factors affecting utilization of ODL; and d) the research challenge, questions and scope. In Section 2, research methods and materials are given. Section 3, provides research findings, which are discussed in Section 4. Finally, the concluding remarks are provided in Section 5. 


\subsection{ODL in International Development Agenda, Frameworks and Policies}

World over, ODL approaches such as e-learning, online learning and blended learning, are widely acclaimed as methods for attaining universal access to quality, flexible and lifelong learning opportunities. International, regional and national development frameworks and protocols are all awash with flamboyant visions aimed at increasing adoption and utilization of ICTs for pedagogical purposes.

Sustainable Development Goal No. Four alludes to the use of ICTs for ensuring inclusive and equitable quality education for promoting lifelong learning opportunities for all.

The 2017 European Union Agenda on Higher Education considers "well-designed [technology driven] higher education programmes and curricula" as one of the solutions for tackling the challenge of "skills mismatches and promoting excellence in skills development" [2, p.5]. The Agenda emphasizes technology driven programmes and curricula because, "Technology offers new ways to structure the way learning and teaching are organized, including through open, online and blended learning to increase flexibility and teacher-student interaction" [2, p.5]. Technology has the potential to permit authentic learning approaches where students learn by simulating real-world problems in the classroom.

\subsection{Regional Commitment to ODL}

The Common African Position (CAP) on Post-2015 Development Agenda [1, p.8] implores African countries to strengthen the "science and technology component of education curricula" as a means to achieve excellence in education. The CAP further stresses the need to "achieve excellence in human resources capacity development through an improvement in the quality of education and training by ... increasing the use of ICT in education", among other strategies (p.9).

\subsection{National Commitments to ODL}

At national level, nations have formulated development agenda, policies and strategies promoting ODL approaches.

South Africa has been at the forefront of promoting ODL approaches. The University of South Africa (UNISA), the single largest open distance learning university became the "first public university in the world to teach exclusively by means of distance education in 1946" [9]. South Africa's ICT in Education policy has been evolving since 1995 [3]. In that year the Technology Enhanced Learning Initiatives (TELI) was established followed by a feasibility study to establish a Dedicated Educational Channel. In 2001, the National Department of Education and the Department of Communication jointly released a Strategy for ICT in Education, which resulted into the development of the e- Education White Paper adopted in 2004. South Africa's ICT in education policy had a goal to have every learner in pre- university education being ICT capable by 2013 .

Similar efforts for promoting ICTs in education are evident in other countries. In 2003, a National Policy on ICT was developed in Uganda [3] and later revised in 2012. The first version took special recognition of the role of ICT in fostering lifelong learning opportunities for all Ugandans. In that policy, ICT integration in the education curriculum was articulated as one of the strategies for providing improved literacy and building a cadre of competent human resource for the country. This vital role necessitated further policy articulation of use of ICT in education. As such the need for a standalone policy for ICT in education became apparent.

In 2006, Uganda developed its first ICT in education policy. This policy has since enabled the following achievements; development of guidelines on the use of ICTs in schools; signing of an agreement with Microsoft to subsidies educational software licenses and training of teachers in addition to setting up other activities for implementation; budgeting for ICTs for secondary schools; negotiation with ICT service providers to subsidize rates for ICT systems; training teachers in ICT skills; introduction of Computer Studies as a subject in secondary schools curriculum; and provision of funds and infrastructure for ICTs in some schools.

At higher education level, the White Paper derived from McGregor Report (2008) of the Visitation Committee to Public Universities in Uganda recommended a phased expansion of distance education in public universities, immediate establishment of an Open University and integration of e-learning in conventional classrooms.

In 2012, Uganda revised the National ICT Policy to keep pace with the global ICT terrain. In that policy strategies for use of ICT in education are provided to include: review of curricula at all levels of education so as to improve quality and learning experience; improve the level of investment of educational ICT equipment, software as well as broadband connectivity at all institutions of learning; train teachers in ICT pedagogical skills; establish educational networks for sharing educational resources; promote the growth and implementation of e-learning; and create opportunities and provide assistance for the disadvantaged, people with special needs, women and the youth to acquire ICT skills.

The commitment to integrating ICTs in education is also enshrined in Uganda's Vision 2040. This Vision aspires to provide access to affordable quality health and education services to all Ugandans through flexible teaching and learning methods employing ICTs.

The articulations and acclaims in the different development agenda, frameworks and policies provide a clear indication that different governments be thy in the 
developed or developing regions have embraced the vision of adopting ODL approaches and integrating ICTs in classroom based pedagogy. Primary and secondary schools and higher institutions of learning have similarly formulated policy and strategy regimes aimed at fostering the smooth diffusion of ICTs in teaching, learning, student support and administration.

\subsection{Institutional Commitments to ODL}

Most universities in Africa have formulated policies and strategies for promoting ODL approaches. The Makerere University Strategic Plan 2008/09 - 2018/19, demanded for the introduction of open, distance and e-learning $(\mathrm{ODeL})$ delivered programmes in at least six units of the University (Makerere University, 2008). Similarly, a task force setup by Makerere University Council on Job Evaluation, Re- Organization of the Staff Structure and Financing of Makerere University recognizes the critical role played by ICT in enhancing access to quality education through ODeL pedagogy. The report further recognizes Government's effort towards securing a loan from the African Development Bank to support infrastructure development including that for delivering education through ODeL pedagogy (Omaswa, 2014).

To actualize the demand for diffusion of ODeL at Makerere University, the University's ICT policy called for the development of a separate dedicated policy on ODeL. This policy was developed and approved in October 2015 (Makerere University, 2015). The policy provides a fertile ground for the diffusion of blended learning at Makerere University. It articulates the position, target clients, financing, staffing, study materials, delivery, discipline development, quality assurance system, management and administration and technological support of/for ODeL at Makerere University. It upgraded the Department of Open and Distance Learning into the Institute of Open, Distance and e-Learning with the mandate to oversee the development and growth of ODeL approaches in the entire University. It further spells out the relationship between the Institute of Open, Distance and e-Learning and other academic units in the dual-mode Makerere University.

Kyambogo University, another public University in Uganda, ratified its ICT Policy in 2014 (Kyambogo University, 2014). In this Policy, Objective No. 7.5 states as “... to strengthen capacity of innovations in ICT development, use of the technology and general work flows". Among the ten (10) strategies listed to actualize Objective No 7.5 is Strategy No. (vii) which targets "harness[ing] ICT potential in enhancing online and distance learning in order to maximize flexibility in education and reach out to a wider coverage of prospective learners" (p.16-17).

Other public universities too have put in place ICT policies that articulate the need to implement blended learning. Mbarara University of Science and Technology (MUST), in its 2014 ICT Policy promises to “... operate an E-Learning software platform and facilities in accordance with the University's E-Learning policy (Mbarara University, 2014, p.12). Busitema University Strategic Plan 2014/15 - 2018/19 has a strategic action to "develop online processes and electronic information centers" (Busitema University, 2014, p.10). Gulu University undertook an e-learning needs assessment from which a proposal of strategy for e-learning was derived [7]. The draft strategy proposes to establish a dedicated e-learning unit to nurture and manage distance and e-learning at Gulu University.

\subsection{Some ODL Projects}

African countries have benefited substantially from ODL grants from development partners. The first ODL project in Africa was the African Virtual University (AVU) project initiated in 1997 (Okuni, 2000). The AVU was a satellite based distance education project mooted and sponsored by the World Bank under its Information for Development (infoDev) programme. It was an ODL project, which comprised of a network of Internet facilities with its own Website. It employed a multi-media approach to teaching and learning. The learning packages comprised of live or pre- recorded lectures transmitted by satellite at specific times from universities in the United States and Ireland and viewed on television screens in Africa. It also involved hand-outs, textbooks and other material transmitted electronically (ibid).

Since the AVU time, numerous ODL projects have been implemented in different Universities in Africa. The AfDB HEST V Programme is implementing a component to provide ICT infrastructure at public universities in Uganda. Specifically, this programme has provided about USD 1 million for procuring e-learning equipment and building capacity for e-courseware development at Makerere University. In 2013, Makerere University received a USD 3 million NORAD/NORHED grant for the Distance Education Leapfrogging Project (DELP). DELP was aimed at leapfrogging $1^{\text {st }}$ generation distance education into $4^{\text {th }}$ and $5^{\text {th }}$ generation distance education. In 2017 Makerere University, Open University of Tanzania, State University of Zanzibar, Strathmore University, Kenyatta University and Rwanda University started participating in a GBP 2 million DfID/SPHEIR supported project titled: Partnership for Enhanced and Blended Learning (PEBL). PEBL is aimed at sharing scarce faculty in the six (6) partner universities using blended teaching.

In 2014, Gulu University participated in a MAGAART (Maseno University, Gulu University, Aarhus University, Roskilde University and Tribhuvan University) partnership under the project, Building Stronger Universities in Developing Countries (BSU), funded by 
the Danish International Development Agency (DANIDA), with Aarhus University in Denmark as project leader and Maseno University as key partner in the e-learning and problem- based learning component. The partnership helped undertake an e-learning needs assessment survey and produced an e- learning strategy for Gulu University. Other universities in Africa have implemented one or more projects in e-learning.

\subsection{ODL Conferences in Africa}

Since 2006, the World has been converging in Africa, on an annual basis, to share experiences at a conference popularly known as E-Learning Africa (eLA). In 2017, eLA took place in Mauritius. In 2018, it took place in Kigali. In 2019, it will be in Morocco. The Conference has been bringing together experts and stakeholders engaged or interested in e-learning and ICT-based training, education and development on the African continent. It has been a meeting point for leading international e-learning suppliers, manufacturers and service providers with potential consumers of e-learning products and services. Other conferences on ODL approaches have been held on the African continent including: DETA (Distance Education and Teacher Education in Africa) convened by the University of Pretoria; Teaching and Learning Festival and CSET ODL Conferences organized by UNISA; eLearning Innovations Conference \& Expo Kenya, taking place annually in Nairobi, Kenya, the Distance Education Leapfrogging Project Workshop held annually at Makerere University, and many others.

\subsection{Utilization of ODLApproaches}

Studies on utilization of ODL approaches in Africa indicate low adoption levels despite the most common belief that ODL approaches are a panacea to solving the challenge of bulging student numbers in conventional education institutions. For example, in Uganda, the bulge is orchestrated by introduction of free primary and secondary education. Every year an average of 64,000 candidates qualify to join university but existing brick-and-mortar infrastructure in Ugandan universities can only accommodate less than half of this number. At Makerere University, students studying through ODL are less than $10 \%$ (about 3500 of 40,000 ) of the entire population in the university. In Kenya, the bulge is due to the generous Government loan scheme where every Kenyan student who qualifies to join university and wishes to get a tuition fees loan can indeed access one. The brick-and-mortar infrastructure in universities of these countries cannot accommodate all the qualifying applicants. A quick fix would have been Governments setting up open universities but this is not the case. The proposal to start the Open University of Uganda has since 2000 appeared in the Ministry of Education and Sports annual policy statements as an unfunded priority. This has left individual universities to tussle it out on their own.

Makerere University Business School (MUBS), for example, has since 2006 explored possibilities of using e-learning to increase access to its programmes at its study centers with limited success [4]. MUBS e-learning integration approach has been that of a one to one mapping of traditional teaching methods onto e-learning sphere fearing that when another approach is used it may compromise quality standards. In his SAMR (Substitution, Augmentation, Modification and Redefinition) Model, Puetendura would place MUBS approach in the category of use of ICTs to substitute manual processes [5]. When ICTs are merely used as tools to substitute manual processes, for example, word processor being used in place of a typewriter, the quality of the print is improved but costs may not necessarily be reduced.

Universities are wary about cost, quality and demographics while choosing to integrate e-learning in their pedagogical processes [8]. To many, they are quick to suggest introduction of e-learning whenever they think of reducing costs associated with traditional face-to-face approaches only to be shocked by the initial high cost of setting up the environment for true e-learning experience. Many have a feeling that the products from online learning/e-learning are of inferior quality as compared to those from campus based education. In other instances, there is a belief that e- learning/online learning is suitable for adults with multiple responsibilities. Are these hypes or realities?

Low use of ODL approaches has in some instances been attributed to lack of awareness and training on ICTs for pedagogy. At Makerere University, whereas the majority of academic staff are ICT literate (over 90.0\%), there is insufficient use of ICTs in pedagogical processes. At this University, the personal computer is by far the most highly $(84.6 \%)$ used ICT. This is followed by the Internet (58.3), Power Point Projectors (52.4\%), e-mail (51.5\%), mobile devices $(34.3 \%)$ and the institutional learning management system - MUELE (33.0\%) [5, p.3]. Social media applications and emerging educational technologies such as Face Book, Twitter, Second Life, e-Portfolios, Scoop it and many others are yet to see their usefulness at Makerere University. Despite being in place for over 10 years, MUELE was only in the sixth position in terms of ICTs that were always used by staff for pedagogic activities. The main reasons advanced for not being the most used of the educational technologies relate to lack of knowhow on how to use the equipment or application and lack/limited access to the equipment/application. "I do not know how to use Second Life and I have never even heard about it, how do you expect me to use it", asked one of the respondents. Another respondent said, "we do not have access to most of the educational technologies. The few computer labs that are available are always congested with students". Besides, the pedagogical affordances of most of the 
educational technologies are not known to many. "What will I be using it for if I used Drop Box in my class?", asked one of the respondents (ibid). This suggested the need for awareness and training.

In 2011, the Inter University Council for East Africa, commissioned a study aimed at enhancing the capacity of East African universities to utilize ICT for sustainable regional development. The study undertaken by [6] established that key facilities for basic ICT training were readily available in most universities but those for pedagogical ICT training was constrained. For instance, Internet connectivity was still a very big challenge to most universities and as such online learning was highly constrained. The study identified areas with acute lack of skills. Skills were found lacking in: i) the development of online courseware, online facilitation and online assessment; ii) utilizing collaborative tools for teaching and learning; iii) use of administrative systems; iv) use of learning management systems; and v) operation of ICT hardware for teaching and learning. From these needs, training programmes were developed.

\subsection{Factors for Low Utilization of ODLApproaches}

Low utilization of ODL approaches to teaching and learning stems from several factors - including lack of flexibility in platforms, inability to strike a balance between the needs of the different stakeholders, negative stereotypes, limited enforcement of policies and strategies, limited human capacities for ODL approaches and wrong assumptions about ODL approaches.

Many of the platforms used for e-learning, for example, Moodle, Blackboard, Its Learning, Fronter, etc. do not provide the flexibility that instructors need to support learning for a variety of students in various situations (Kanovsky \& Or-Bach, 2001).

It is always not easy to strike a balance among the ODL interest groups. Students, lecturers, technicians, policy makers, employers and many others place different requirements to training institutions (Kanovsky \& Or-Bach, 2001). These varied requirements affect utilization of ODL approaches.

Faculties in most of the universities in Africa are trained and groomed using traditional teacher-centered face-to-face approaches. Requiring them to transit from these approaches to ODL approaches, which are in most cases student centered is demanding for a little more. So in many cases these new approaches will be resisted.

Whereas policies for e-learning have been put in place in most universities, they are lukewarmly enforced. Many a university administrator in a traditional face-to-face university, will only be concerned with the question, 'have the students been taught' not the question 'how have the students been taught?'

Limited capacity to integrate ODL approaches into traditional pedagogy. Majority of universities have computer scientists and not ICT pedagogues managing their so called e-learning units. A common mistake in ICT integration is assigning computer scientists to the function of supporting e- learning pedagogy. Computer scientists can build, programme, repair and maintain ICT systems but are not in position to eke out the pedagogical affordances and use of the e-learning tools.

There is wide ranging assumptions that ODL courses are self- service courses. Institutions put in place ODL courses and put them out to students for 'self-service'. Contrary to the common belief, ODL requires facilitators just like the traditional face to face pedagogy. Where they are employed many of the facilitators do not have requisite online facilitation skills.

The initial cost of putting in place and utilizing systems for ODL is high. As such universities start pseudo ODL programmes due to their inability to setup all requisite infrastructure for ODL. This results into poor quality outcomes, which eventually lead to low utilization. Appropriate budgeting for ODL is therefore vital.

\subsection{The Research Problem and Questions}

If there was a match between ODL articulations with its utilization, the majority of institutions of learning would be greatly blended or 'onlinized'. A match would be the desirable situation but this is not the case. What is the missing link? Not enough work has been done in developing methods and frameworks for congruencing ODL utilization with the hype that surrounds it. Kituyi and Tusubira (2013) have proposed a framework for integrating e-learning into higher education institutions in developing countries. Their framework proposes use of projection equipment; use of e- learning methods to teach and face-to-face method to administer tests and exams; harmonization of course content for e-learning and face-to-face during design phase; incorporation of 3D pictures, audio and videos in classrooms among others. This framework simply suggests ICT equipment that should be used in the integration but does not provide mechanisms for upping utilization of these equipment in pedagogy. Another framework worth noting is that suggested in Puetendura's model [5]. This model suggest that ICTs can be integrated through substitution, augmentation, modification and redefinition of education tasks. Again this model too simply classifies ways in which ICTs can be integrated but not how ICT adoption and use can be fomented. In this paper a framework for congruencing ODL utilization to its world-wide articulation and acclaim is provided. This calls for answers to the following research questions:

- What factors explain the high articulation/acclaim levels of ODL approaches in public universities?

- What is the present utilization level of ODL approaches in public universities?

- What factors explain the present utilization levels of ODL approaches in public universities?

- How can utilization of ODL approaches be congruenced with the hype surrounding it? 


\subsection{Scope}

To answer the stated research questions, a study was designed and carried out in public universities in Uganda. These universities bear comparable characteristics with other universities on the African continent and therefore developing regions.

\section{Materials and Materials}

A cross-sectional survey design employing mixed research approach involving primary data collected across public universities in Uganda and secondary data obtained from records and related literature was employed.

\subsection{Population and Location of the Study}

The population of the study was derived from academic staff of seven public universities in Uganda. These included; Makerere University, Gulu University, Kyambogo University, Makerere University Business School, Busitema University, Mbarara University of Science and Technology and Kabale University.

\subsection{Study Elements}

There were 4221 academic staff in the aforementioned universities. Using Krejcie and Morgan (1970) sample determination table, a sample size of 351 respondents was targeted. However, 120 valid responses were returned representing a response rate of $34 \%$. The study elements were selected using stratified random sampling.

\subsection{Data Collection Methods, Tools and Sources}

The study employed a survey method to collect both quantitative and qualitative data from primary and secondary sources.

\subsection{Validity and Reliability of the Tool}

A pilot test was carried out to determine item reliability for the constructs being measured. The Cronbach alpha value for the pilot test was 0.89 ; hence the instrument was classified as having acceptable reliability and therefore no changes were made to the items as argued by Kamarul (2010).

\subsection{Data Analysis}

The returned responses were checked for completeness and accuracy. The data was analysed using SPSS to generate descriptive and inferential statistics.

\section{Findings}

\subsection{ODL Articulation Levels in Public Universities}

So as to understand the extent of articulation of ODL approaches in public universities, staff were asked to respond to a number of questions that would exhibit knowledge of appreciation for teaching with ICTs. The study sought to establish from the staff whether:

- Teaching with ICTs was part of their

- universities academic improvement plans

- They valued ICTs as important tools for teaching

- Teaching with ICTs changed the way students learnt, and

- They advocated for teaching with ICTs

\subsubsection{Teaching with ICTs and Universities Academic} Improvement Plans

The question, 'Is teaching with ICT part of your university's academic improvement plan?' was posed. Responses are presented in Figure 1 below:

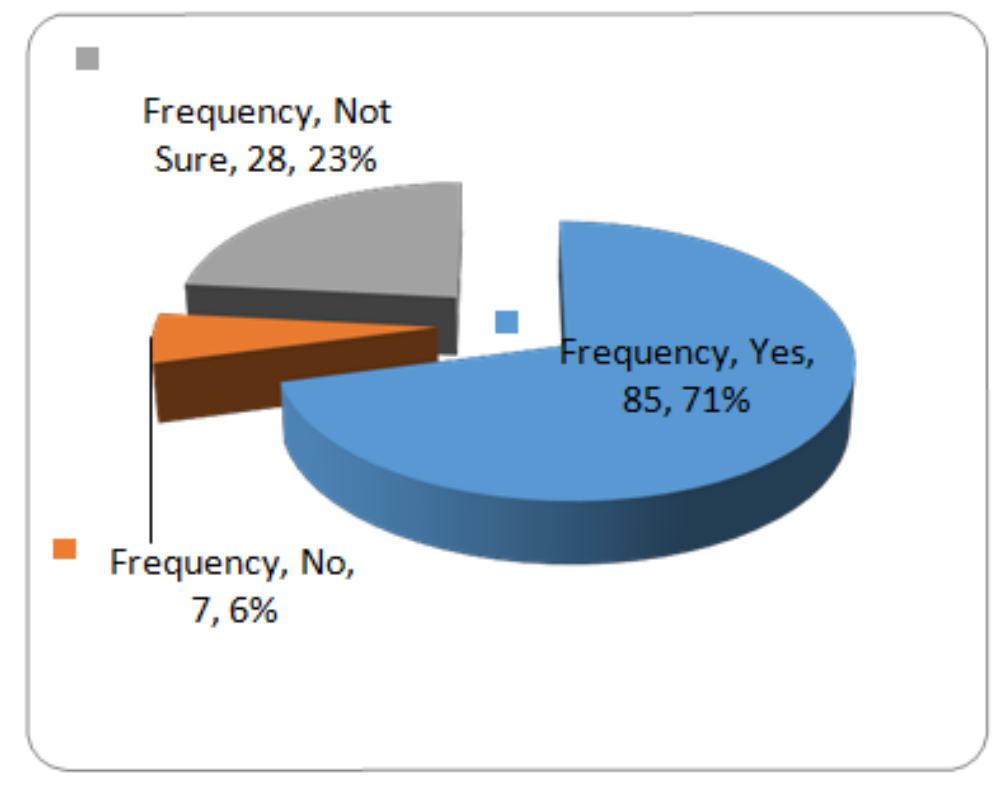

Figure 1. Teaching with ICTs and Academic Improvement Plans 
Figure 1 above shows that universities placed teaching with ICTs as one of their strategic actions for academic excellence since $71 \%$ of the staff interviewed confirmed that e-learning was part of their universities academic improvement plans as opposed to only $7 \%$ who rejected the assertion. This indicates a strong awareness about the prowess of ICTs in pedagogy. This high level of awareness is an important factor that could be leading to a high level of articulation of ODL approaches in educational institutions. However, a sizeable proportion of staff (23\%) lacked knowledge of their universities academic improvement plans which calls for sensitization of staff on their institutions strategic directions.

\subsubsection{Value of ICTs as a Teaching Tool}

Through the question, 'How important has the use of ICT been in your University's academic programmes', staff's views regarding the value of ICTs in pedagogy were established as shown in Figure 2 below.

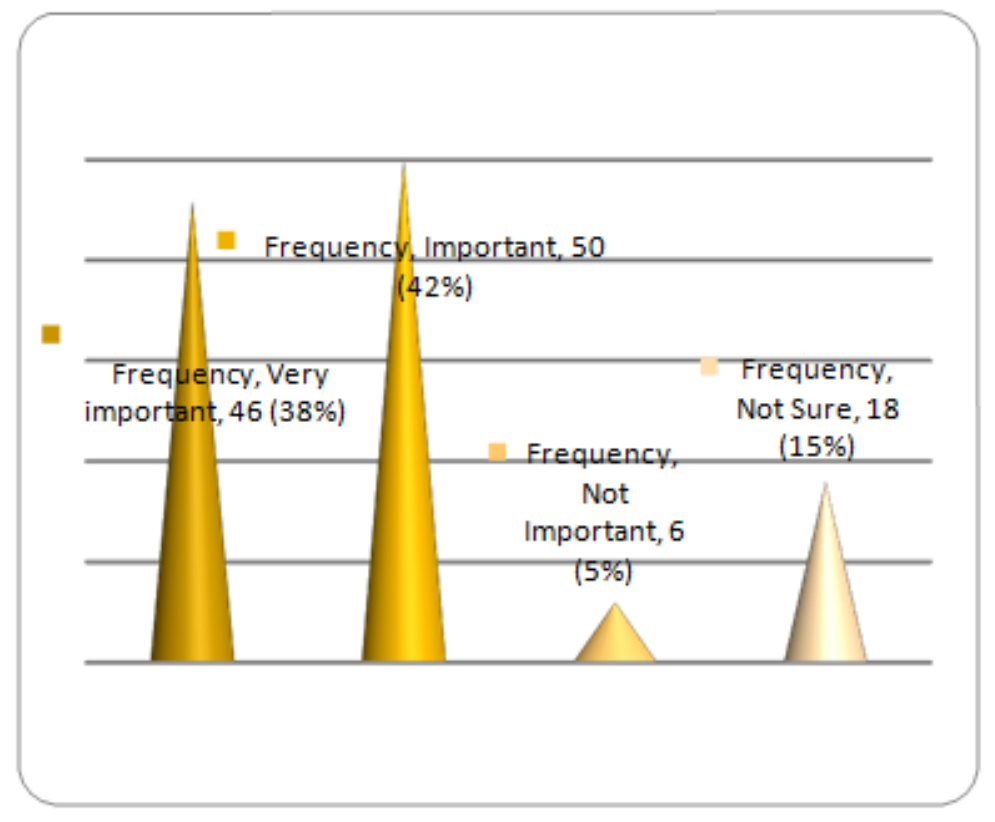

Figure 2. Importance of ICTs in University Academic Programme

From findings in Figure 2 above, it is without question that ICTs are of great value to teaching and learning. About $88 \%$ of the respondents indicated that using ICT in their universities' academic programmes was of paramount importance arguing that ICT use and access has improved areas of teaching, research and publications; that ICT use continues to improve the teaching and learning quality; that ICT use simplifies the preparation of teaching materials; that ICT use helps in benchmarking of course materials and programmes with other universities online and that we were in an ICT era where everyone must be encouraged to use ICT infrastructure. Fifteen percent of the respondents were not sure while 5\% indicated that the use of ICT in their universities' academic programmes was not important urging that ICT was not emphasized in their universities' teaching and that no policies on ICT use were in place; that there was general lack of interest by some teaching staff and that there was constant Internet failure and high prices charged for Internet data, making access and use limited. The unlimited perceived affordances of ICTs for teaching makes its articulation wide spread.

\subsubsection{Value of ICTs as Learning Tools}

To establish whether teaching with ICTs had had any profound impact on the way students learnt, the respondents were asked to provide their views in a Likert scale form to the proposition that 'Teaching with ICT in my University can change the way the students learn'. Responses are provided in Figure 3 below: 


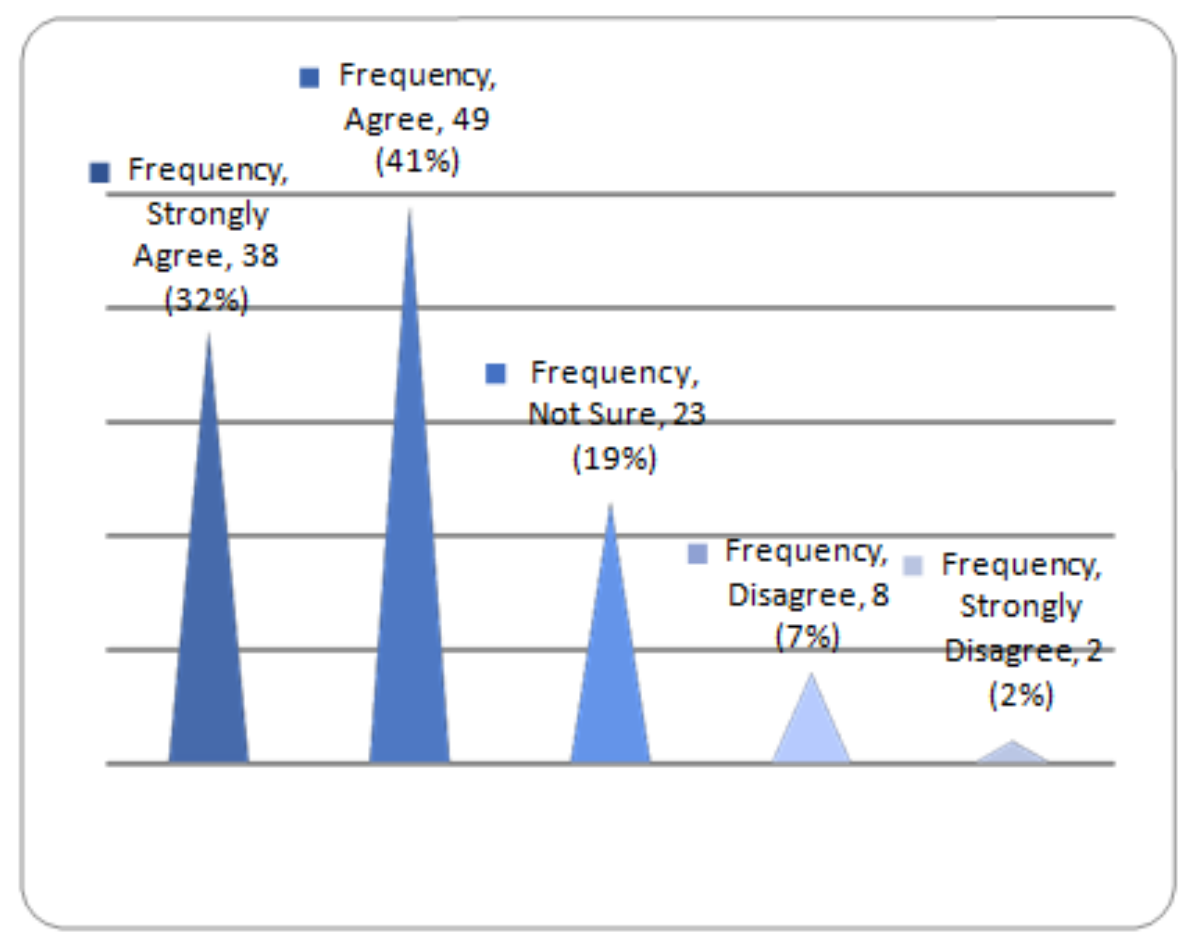

Figure 3. Teaching with ICT Can change the way students learn

Majority (73\%) of respondents were in agreement that teaching with ICT in their universities had changed the way the students learnt with only 9\% disagreeing. A good proportion of respondents (19\%) were not sure whether there was any change. Respondents who were in agreement argued that students were able to discover, innovate and learn on their own; that students had gained good communication skills, research skills; that ICT was being used as a tool for problem solving especially the social media; that ICT continued to improve on students' creativity and innovativeness; that students were able to do online practicals and that ICT had led to student centered learning. On the other hand, those who disagreed argued that it was quite difficult to determine since there were no previous studies done to understand if there was change; that there was limited use of ICT when delivering lectures and that there was insufficient ICT infrastructure in their lecture rooms. The unlimited perceived affordances of ICTs for learning makes its articulation wide spread.

\subsubsection{Staff's Views on Increased Use of ICTs in Pedagogy}

The high level of articulation of ODL approaches in international, regional, national and institution development frameworks and policies, is quite well reflected among staff of universities as well. When asked to respond to the assertion that 'There should be increased use of ICT in Teaching \& Learning', all the respondents were in total agreement arguing that ICTs have the potential to improve knowledge levels of both students and staff, that ICTs can improve speed and accuracy, that ICTs enhance storage of data and networking, that ICTs improve lecture delivery, that ICTs are a cost cutting technologies as they save on paper and that ICT use was swifter, saves time and would considerably reduce loss of students results. The need to improve pedagogic and administrative support systems precipitate the need for ICTs in education institutions and hence the wide articulation.

\subsection{State of Practice of ODL Approaches in Public Universities}

Staffs in universities highly articulate ODL approaches as modern pedagogical approaches that should be embraced. Is this by word of mouth or by practice? To answer this question, respondents were asked questions that would establish the level of use of e-learning in their universities. These included: whether their universities had any e-learning systems in place, frequency of access of the system, location, purpose and time of access to the system and number of courses taught with ICTs.

\subsubsection{E-Learning Systems in Universities}

Respondents were asked to tell whether their universities had installed a learning management system or not. Responses are given in Figure 4 below: 


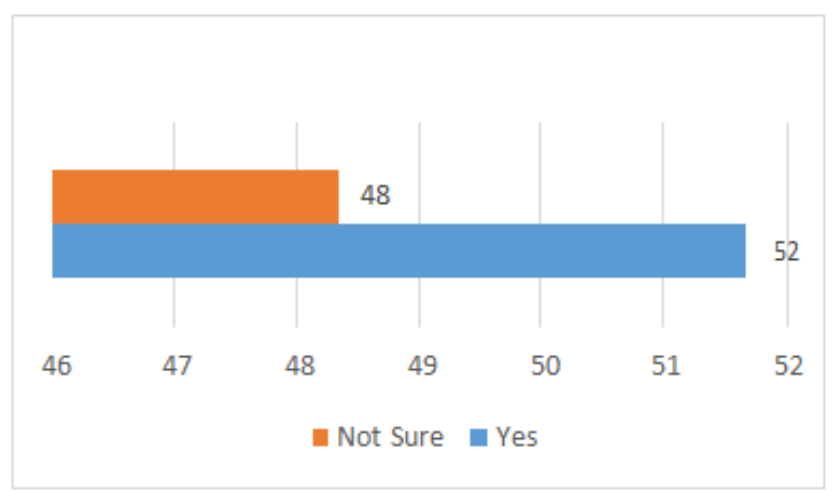

Figure 4. Existence of a Learning Management System

Whereas articulation of ODL approaches was high in public universities, it was surprising to find that almost half of the respondents were not aware of the existence of a LMS in their universities. This is evidence enough to prove the assertion that articulation of ODL approaches is high but their utilization is still low. Such a scenario occurs when staff are not sensitized or trained on the use of the platform if it exists. The $52 \%$ who indicated existence of a LMS in their universities mentioned Moodle as the most common platform across all universities. Moodle had been installed and variously customized and named in the different universities surveyed. Makerere University's Moodle was renamed MUELE, that for Mbarara University of Science and Technology was renamed MUST-LMS and that for Kyambogo was called MY-CAMPUS.

\subsubsection{Frequency of access to the LMS}

A probe into access to the LMS installed was undertaken through the question, 'How often do you access your University's LMS?' The results are presented in Figure 5 below.

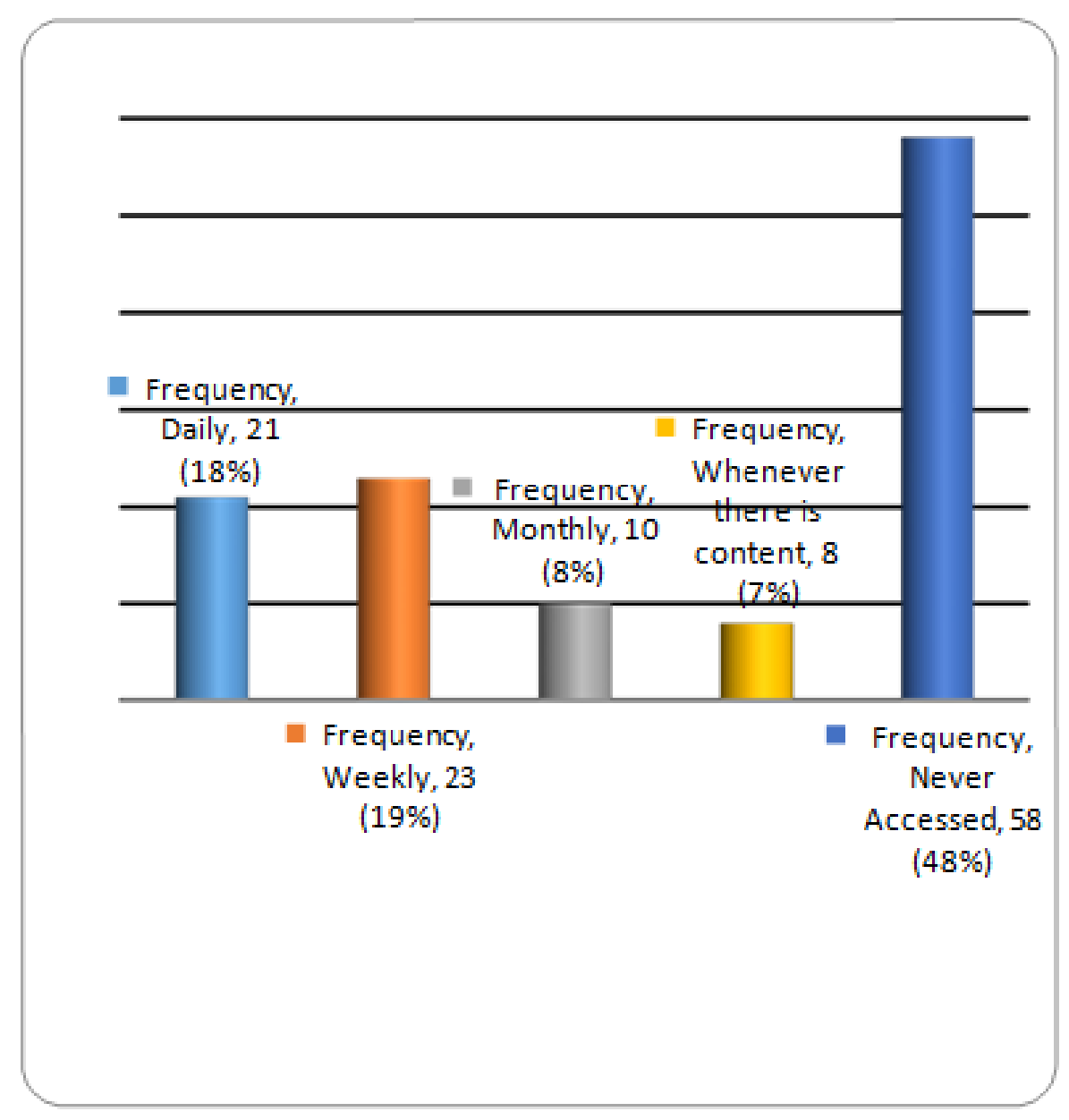

Figure 5. Frequency of Access to Institutional LMS 
Figure 5 above shows that access to institutional LMSs is quite decimal. About half of the teaching staff have never accessed their institution's LMS. Fifteen percent infrequently (monthly + whenever there is content) accessed the LMS while only $37 \%$ frequently access the system. This access institutional LMSs is still in its infancy. This calls for popularization of LMS use, harnessing the affordances of widely accessible ICTs such as mobile phones and social media and blending of ICTs for pedagogical purposes. In Muyinda (2015) it is reported that $100 \%$ of students and faculty own mobile phones with over $75 \%$ of them being smart.

\subsubsection{Point, Purpose and Time of Access to LMS}

The point of one's usual access, purpose and time for usual access to a LMS were investigated to establish whether these could be the determinants to one's frequency of use of a LMS. Respondents were asked the questions, 'From where do you mostly access your University's LMS?'; 'State the purpose for which you access your University's LMS', and 'What time is most convenient for you to access your University's LMS?' All respondents $(100 \%)$ who had ever accessed their institution's LMS did so from their offices (their workplaces). They accessed the LMSs to develop e-content, upload and update teaching materials, set assignments and check on students who log onto the system. The majority (53\%) accessed it anytime, $32 \%$ in the morning, $6 \%$ in the afternoon and $8 \%$ at night. E-Learning is meant to increase flexibility in teaching and learning. If staff were only tethered to their offices for access to the institution's LMS, it goes without saying that students are equally tethered in institution's computer laboratories for access to LMS. Such a condition is not favorable for ODL.

For conventional classroom based programmes, lecture rooms were not equipped with required classroom-based ICT systems yet less than $10 \%$ of students owned personal laptop computers but had mobile phones. Institutions should render their LMSs for ubiquitous access through mobile phones by both staff and students.

\subsubsection{Course Units on the Institution's LMS}

The question, 'Of the course units you teach, how many are on your University's LMS?' was posed to further determine the extent of use of the LMS. Figure 6 below shows the responses.

About $50 \%$ of the lecturers do not have a single course unit running on their institution's LMSs. Only 3\% have three course units active on the LMSs. Only $22 \%$ have one course running. A probe into whether the running courses were designed following online learning course design principles was done. The probe indicated that the courses simply consisted of repositories of lecture slides and pdf content for students to 'serve' themselves. No interactive activities were evident; neither was their e-moderation by the lecturers. This calls for capacity development of lecturers in online courseware development and facilitation.

Clearly, the foregoing findings re-affirm the fact that ODL utilization is extremely low. The factors causing the low utilization levels were investigated.

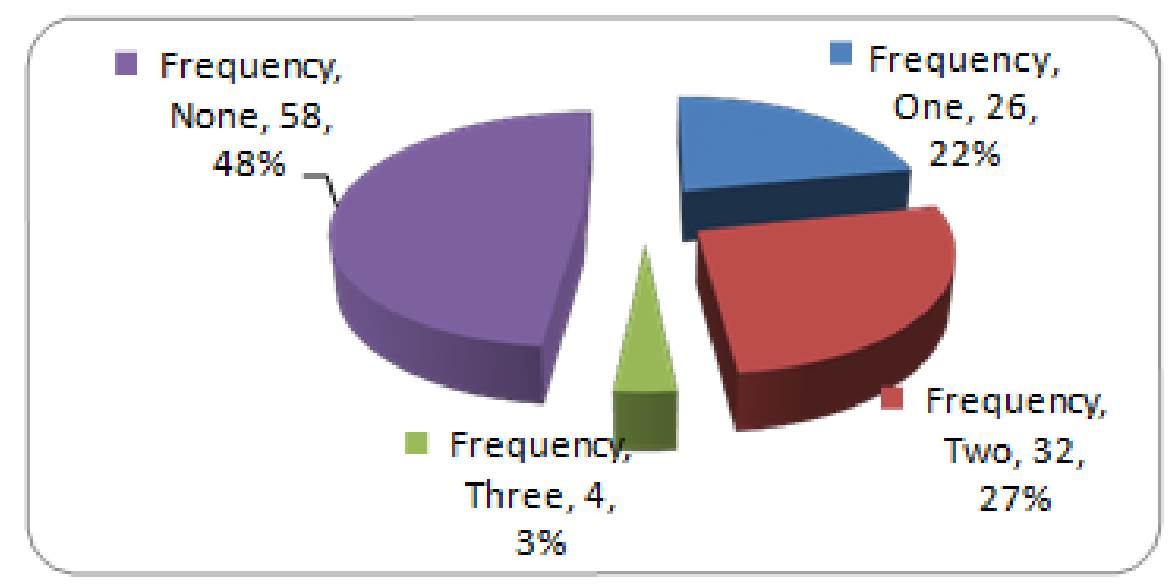

Figure 6. Courses per Lecturer on the Institution's LMSs 


\subsection{Factors for the Low Utilization Levels of ODL Approaches in Public Universities}

From the study, the factors for low levels of utilization for ODL approaches stem from institutional and individual capacity constraints.

Institutionally, respondents indicated that their LMSs were not fully functional and some were dysfunctional and could not be accessed on mobile phones. The majority of the institutions' bandwidth was insufficient for seamless access to and uploading of large files onto LMSs. A big proportion of faculty did not have access credentials to the LMSs and let alone computers in their offices. Power supply was intermittent and in majority of universities, Internet connectivity was poor. Furthermore, even if institutions had ODL policies and strategies, these were hardly being enforced. Teaching with ICTs was mainly found among faculty who had developed an individual passion for e- learning rather than an institutional requirement. Apart from Makerere University, all the other public universities in Uganda had not setup an ODL pedagogy unit. The staff supporting ODL in those universities were computer science majors with no special training in ODL pedagogy.

Individually, there were attitude and capacity factors that led to low utilization of ODL approaches. Attitude wise, all faculty and administrators in universities considered in the study schooled using conventional classroom based approaches. They regarded ODL approaches as being inferior approaches of study. Further, they loathed the time and effort required for preparing a quality ODL supported course. Similarly, the school system in Uganda was majorly a classroom chalk and talk based system. Students, parents, policy makers and other stakeholders were more familiar with this type of system and were less likely to adopt another system.

Capacity wise, faculty lacked the requisite skills for using LMSs, developing e-courses let alone facilitating them. When respondents were asked to indicate whether, they had ever received training on use of a LMS, $62 \%$ indicated to the contrary while only $38 \%$ responded in the affirmative. All those who answered in the affirmative agreed that the training received had resulted in their active use of the LMS system.

The situation was not any different when respondents were asked the question, 'Have you ever developed and hosted a course online on any LMS? ' Seventy-nine percent indicated they had never while only $21 \%$ had ever. Of those who had ever developed an e-course only $14 \%$ had followed known e-courseware design principals while the rest had just put content online. Lack of use of online learning design principals was attributed to lack of training in e-courseware development as only $27 \%$ indicated having had training in e- courseware development. No wonder all $(100 \%)$ respondents were desirous to have training in e-courseware development.

Similarly, when respondents were asked the question,
'Have you ever facilitated (taught a course) using purely onlinele- learning methods?', the majority (92\%) answered 'No'. Interestingly, all $(100 \%)$ of the respondents who indicated they had ever facilitated a course online, denied following known online/e-moderation principles. The major reason advanced for this state of affairs was lack of training in online facilitation for the majority (92\%). However, all faculty interviewed were willing to get training in online facilitation.

\section{Discussion}

The findings have confirmed that the general view in literature that ODL approaches are highly acclaimed but lowly utilized. So as to congruence low utilization with the high acclaim, findings call for the need to address the causes of low utilization. From the findings, low utilization is caused by factors stemming from institutional and staff capacity constraints. Institutional constraints relate mainly to infrastructural constrains ('hard' issues) while individual constraints relate to attitude and skills issues ('soft' issues).

This therefore implies the need for 'hard' and 'soft' solutions to congruence ODL utilization with its high acclaim. 'Soft' congruencing relate to dealing with people and policy issues while 'hard' congruencing relates to dealing with infrastructural challenges.

\subsection{Soft Congruencing}

Fifty-two percent of respondents indicated that their universities had installed a LMS. In a framework for integrating e-learning in teaching and learning [4], emphasis was put on installing ICT equipment in lecture room such as projectors, etc. Other projects, as well (e.g. AfDB HEST V) have emphasized procurement of hardware for connectivity and access to Internet. Emphasis has all along been majorly placed on putting in place hardware systems (infrastructure) to support ODL. Little has been invested in the people - the 'soft' side. The 'soft' investments relates to creating a positive attitude and awareness towards ODL approaches amongst all stakeholders - students, teachers, parents, policy makers, employers and other stakeholders. In particular, ODL practitioners need to be attuned to contemporary pedagogical realities through continuous training and retraining. The realities are drawn from the skills and attributes identified as being vital for the 21st Century learners and workers. According to UNESCO (2015) and World Economic Forum (2016), a $21^{\text {st }}$ learner and worker should have effective oral and written communication and collaboration skills. They should have grit and resilience; empathy and global stewardship; self-regulation; and curiosity and imaginative skills. They should be agile and adaptable. 
Contemporary realities and indeed ODL demand for faculty who use student centered methodologies. Unfortunately, most faculties are bred and attuned to the teacher centered paradigms which have a philosophical mismatch with teaching and learning paradigms for ODL. ODL faculty need orientation and training in digital skills including ability to: conduct effective online searches; find $\&$ evaluate web based materials; use digital assessment tools; create, edit and share digital content; use social media for professional development and create visually stimulating graphics. Faculty need to be trained and retrained in the use of various ICT tools for teaching and learning, e-courseware development and facilitation.

Further, contemporary realities require addressing the following 'soft' dimensions

- Making teaching through using ODL approaches more attractive

- Motivating faculty to develop online artifacts and working online

- Making online working conditions favorable

- Ensuring appropriate institutional and national policies on ODL

- Ensuring improved internal efficiencies for ODL

- Better utilization of existing resources including appropriate budgeting

- More creative and innovative approaches to provision of education - willingness to embrace change

- Regular support supervision and CPD provided by dedicated ODL support staff

- Better planning and institutionalization of projects for sustainability of initiatives.

- Quality assurance frameworks and practices provision of better and quality learning

- More research - especially on ODL student support and quality assurance

\section{2. 'Hard' Congruencing}

When respondents were asked the question, 'What should be done to encourage you and others to actively use your University's LMS for teaching?' they mentioned several hardware interventions that need to be made. According to them, all universities must install and operationalize a LMS, they should increase on their bandwidth for improved access, they should setup a dedicated ODeL units with dedicated ODL support staff who should include among others, ODL pedagogy experts, educational technologists, programmers and multimedia specialists. They should install wireless Internet access points and upgrade their Internet infrastructure in all their centers. They should invest in standby power generators or alternative power sources to avoid interruptions to the systems, they should develop LMS system applications for mobile phones to ease on accessibility and usage; they should harness the affordances of widely accessible ICTs such as mobile phones and social media and blend ICTs for pedagogical purposes.

\section{Conclusion and Suggestions}

ODL presents a good opportunity to increase access to education but the will of the people, their skills capacity and policies to scaffold ODL use are yet to be developed to take off levels. Similarly, institutions will need to invest in hard infrastructure to support ODL. As such to congruence ODL utilization with acclaim, investments in ODL should balance between soft and hard infrastructure for ODL. Since many stakeholders are wary about the quality of learning from ODL approaches, a comparative longitudinal research need to be carried out to measure learning outcomes from ODL and conventional pedagogy graduates.

\section{Acknowledgements}

We are very grateful to SIDA for funding the research that culminated into this paper. We also grateful to Makerere University for according us the time to undertake this research.

\section{REFERENCES}

[1] African Union (2014). The Common African Position (CAP) on the Post-2015 Development Agenda. Addis Ababa, ETHIOPIA. Accessed from http://www.who.int/pmnch/development_agenda.pdf?u $\mathrm{a}=1$ on August 3, 2018

[2] European Union (2017). Communication from the Commission to the European Parliament, the Council, the European Economic and Social Committee and the Committee of the Regions. Brussels, Belgium. Accessed from

https:/ec.europa.eu/education/sites/education/files/he-com -2017-247 en.pdf on August 3, 2018.

[3] Farrell, G., \& Isaacs, S. (2007). Survey of ICT and Education in Africa. A Summary Report Based on 53 Country Surveys. Accessed from

https://www.infodev.org/infodev-files/resource/InfodevDo cuments 353.pdf on December 9, 2018

[4] Kituyi, G. \& Tusubira, T. (2013). A framework for the integration of e-learning in higher education institutions in developing countries. International Journal of Education and Development using Information and Communication Technology (IJEDICT), 2013, Vol. 9, Issue 2, pp. 19-36

[5] Lubega, T. J., Mugisha A.K., \& Muyinda, B. P. (2014). Adoption of the SAMR Model to Assess ICT Pedagogical Adoption: A Case of Makerere University. International Journal of e-Education, e-Business, e-Management and e-Learning Vol. 4 No. 2, pp. 106-115. Available at http://www.ijeeee.org/Papers/312- CZ607.pdf 
[6] Lubega, T. J \& Muyinda, B. P. (2011). Developing Staff - Training Programmes in ICT That Address Strategic Needs of Universities in East Africa. A report for the Inter University Council of East Africa in the Project on Enhancing the Capacity of East African Universities to Utilize ICT for Sustainable Regional Development.

[7] Ogange. O. B. (2014). Activity report on e-learning needs assessment and strategy at Gulu University, Uganda. Accessed from www.magaart.org on August 5, 2018

[8] Tusubira, F. F and Mulira, N. 2006. "Integration of ICT in Higher Education Institutions: Challenges and best practice recommendations based on the experience of Makerere University and other organizations". Retrieved February 16, 2008 from http://iucea.org/downloads/8.\%20Integrati on\%20of\%20ICT\%20in\%20Higher\%20Education\%20Institu tions.d oc-

[9] UNISA (2017). The leading ODL University. Accessed from

http://www.unisa.ac.za/sites/corporate/default/About/T he-leading-ODL-university on September 11, 2017. 